\title{
Spannende Animositäten und Kungeleien
}

\section{Erhard Taverna}

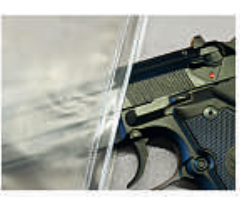

Kalte Allianz

Erster Einsatz für Nikos Pavlides

Kriminatroman

EMH

Telemachos Hatziisaak Kalte Allianz

Erster Einsatz für

Nikos Pavlides

Basel: EMH Schweizerischer

Ärzteverlag; 2011.

256 Seiten. $23 \mathrm{CHF}$.

ISBN 978-3-03754-059-6

erhard.taverna[at]saez.ch
Die Geschichte, die uns Telemachos Hatziisaak erzählt, befriedigt alle Erwartungen an einen spannenden Krimi-Thriller. Der Internist aus Trübbach im Kanton St.Gallen kann nicht nur gut schreiben, er profitiert auch von seiner griechischen Abstammung, denn «Griechenland bietet genug Stoff», wie der Familienvater und Organisator der «PizolCare Akademie für Hausarztmedizin» erklärt. Sein Kommissar Nikos Pavlides, stellvertretender Chef der Kriminalpolizei von Thessaloniki, hat in seinem ersten Einsatz einen diplomatisch heiklen Fall zu lösen.

Bei einer Demonstration vor dem türkischen Generalkonsulat seiner Stadt wird ein Demonstrant beim Übersteigen der Parkmauer aus dem Inneren des Gebäudes erschossen. Damit beginnt eine heikle Gratwanderung zwischen den Anforderungen einer effizienten Polizeiarbeit und den Verschleierungsabsichten der aus Istanbul angereisten, hochrangigen Delegation. Mit Hilfe eines gutpositionierten Freundes aus dem Innenministerium und der tatkräftigen Unterstützung einer überraschend unabhängigen türkischen Kollegin bleiben dem Duo drei Tage Zeit, um den Fall zu klären.

Der Autor beherrscht souverän die Innenund Aussenperspektive einer Ermittlung, die sich gegen den Widerstand des Konsulatspersonals im Umfeld politisch-militärischer Spannungen behaupten muss. Trotz immer wieder neu auszuhandelnder Kompromisse, Rückschläge und überraschender Wendungen kommt es zu einem furiosen Endspiel mit dramatischem Finale. Die Dramaturgie verläuft in konzentrischen Kreisen von aussen nach innen, beginnend mit einem territorialen Konflikt um eine unbewohnte Ägäisinsel, der nach einer Reihe kurzsichtiger Aktionen und Gegenaktionen zum mörderischen Geschehen am Tatort eskaliert. Abgesehen von der geschickt inszenierten Aufklärung erfahren Leser und Leserinnen eine Menge über türkisch-griechische Animositäten und administrative Kungeleien, bis hin zu den appetitanregenden, kulinarischen Offensiven im Dienste der Schadenminimierung.

Der 1967 in der Schweiz geborene Telemachos Hatziisaak hat in Zürich Medizin studiert und im Jahr 2000 die Praxis seines Vaters Kyriakos übernommen. Eine Schwester lebt in Saloniki, sein bester Freund in der Primarschule war ein Türke. Wenn er nicht selber in seiner zweiten Heimat zu Besuch ist, hält er sich über die Medien auf dem Laufenden. Dank der Vertretungen durch eine Allgemeinmedizinerin findet er, trotz zahlreicher Verpflichtungen, die Zeit zum Schreiben. Bereits wäh-

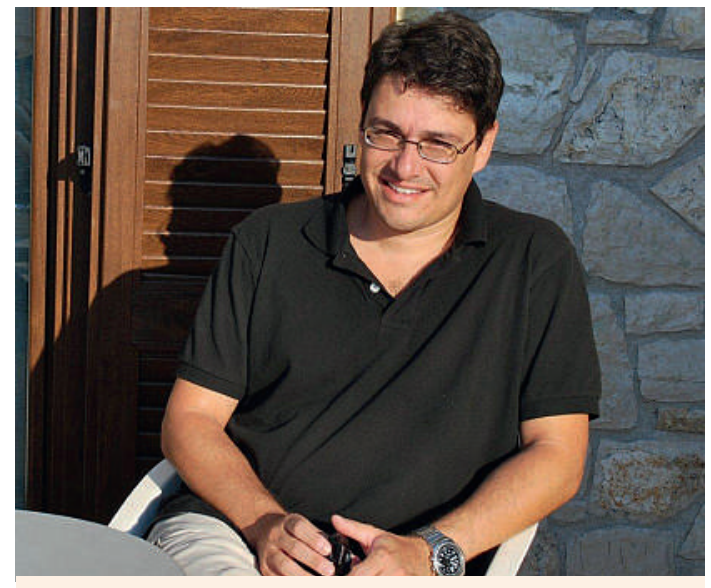

Hat gut lächeln: Telemachos Hatziisaak ist mit seinem Debüt-Krimi ein spannender Thriller gelungen.

rend der Ausbildung zum Facharzt mit dem Schwerpunkt Diabetologie habe er seinen ersten Krimi gleichsam als Übungsstück geschrieben. Er wird in überarbeiteter Form als zweites Buch erscheinen. Nikos Pavlides wird nicht so schnell zur Ruhe kommen, denn sein Erfinder hat schon ein

\section{Mit der Lektüre ist unweigerlich das Risiko der Abhängigkeit oder gar Sucht verbunden.}

drittes Manuskript in der Schublade, und drei weitere Fortsetzungen seien zumindest angedacht. Jeder Autor hat seine Vorbilder. Hatziisaak nennt Petros Markaris, der mit seinem gesellschaftskritischen Kommissar Kostas Charitos international bekannt wurde, weiter den berühmten Thrillerautor der 1930er Jahre, Eric Ambler (u. a. «Die Maske des Dimitrios»), und den Russen Boris Akunin, dessen Kriminalserie in der Ära des Zaren Alexander III. spielt.

Zum eigenen und zum Wohl der Leserschaft ist Nikos Pavlides, auch nach der Rückkehr seines Bypass-operierten Vorgesetzten, eine erfolgreiche Laufbahn zu wünschen. Seine Figur wird sich einprägen, und das Risiko einer Abhängigkeit oder gar von Sucht unweigerlich mit der Lektüre verbunden sein. 